\title{
Shaping Ability of Reciproc R25 File and Mtwo System Used in Continuous and Reciprocating Motion
}

\author{
Vincenzo Campanella ${ }^{1}$, Leonardo Gianni ${ }^{2}$, Antonio Libonati ${ }^{3}$, Gianni Gallusi ${ }^{4}$
}

\begin{abstract}
Aim: Nickel-titanium (NiTi) instruments were designed to be used in continuous rotation mode with controlled speed and torque and a sequence of different sizes. The reciprocating motion was purposed to improve cyclic fatigue of rotary instruments if compared to the conventional rotation. The purpose of this work was to compare the shaping ability of Reciproc R25, Mtwo \#25/0.06 used as a single file, and Mtwo sequence used in reciprocating motion and in continuous rotation.

Materials and methods: Forty-eight endodontic training resin blocks ISO 15, 2\% taper, $7 \mathrm{~mm}$ radius, and a $60^{\circ}$ angle of curvature were shaped with four different protocols. Group I (Rrsf) was shaped with Reciproc R25 used as a single file in a reciprocating motion. Group II (Mrsf) was shaped with Mtwo \#25/0.06 used as a single file in a reciprocating motion. Group III (MSrec) was shaped with Mtwo sequence in reciprocating motion, and finally, group IV (MSrot) was shaped with the Mtwo sequence used in continuous rotation. Preoperative and postoperative images of the simulated canals were taken under standardized conditions and combined exactly. The amount of resin removed was determined at both the inner and outer sides of the canal curvature. The ability of the instruments to remain centered in the canal was determined by calculating a centering ratio. These data were analyzed statistically using two factors analysis of variance (ANOVA) with Bonferroni correction (Bonferroni post-hoc test). Results: Group Rrsf produced a greater enlargement of the canal, especially on the outer side, in the apical and middle third ( $p<0.05)$. Group MSrot produced a lower enlargement in the middle third $(p<0.05)$. Group Rrsf displayed a lower centering ratio in the apical third $(p<0.05)$. Group MSrot displayed a lower centering ratio in the coronal third $(p<0.05)$.

Conclusion: The shaping of simulated canals using a sequence of instruments in continuous rotation resulted in a more centered preparation of the apical third. The reciprocating motion for all tested instruments produced a bigger enlargement of the canals.

Clinical significance: Reciprocating movement results in a more pronounced canal enlargement but appears to be less respectful of the original canal curvature and produces more apical transportation than a sequence of rotary NiTi files with the same ending apical size.

Keywords: Centering ability, Mtwo, NiTi, Reciproc, Reciprocating motion, Root canal preparation.

The Journal of Contemporary Dental Practice (2020): 10.5005/jp-journals-10024-2760
\end{abstract}

\section{INTRODUCTION}

In order to achieve the ideal conditions for a successful root canal filling, it is important to obtain a continuous and controlled tapering with increasing diameters from the apex to the orifice. ${ }^{1}$ The introduction of rotary nickel-titanium (NiTi) endodontic instruments into clinical practice have improved the efficacy of endodontic practice in terms of working time, accuracy, and risk reduction, compared with the previously used manual stainless-steel files. ${ }^{2,3}$ According to many authors, NiTi alloy super-elasticity reduces the incidence of canal aberrations such as zips, ledges, or perforations, especially in narrow and curved canals. ${ }^{4,5}$ Since their introduction, NiTi instruments were designed to be used in continuous rotation mode with controlled speed and torque and a sequence of different sizes. In spite of the high cutting efficiency, in particular cases of curved or narrow canals, many authors reported an increased risk for $\mathrm{NiTi}$ instrument to fail and separate as a consequence of flexural and torsional stresses. ${ }^{6,7}$

The reciprocating motion was purposed as a way to improve cyclic fatigue of $\mathrm{NiTi}$ endodontic mechanical instruments if compared to the conventional rotation. ${ }^{8-12}$ The reciprocating motion stops each rotation cycle of the instrument with a partial rotation cycle in the opposite direction to disengage the instrument from the cutting action and reduce stress accumulation. In 2008, Yared introduced the first reciprocating single file (RSF). ${ }^{13}$ According to the RSF technique, the root canal preparation can be performed
1,2,4 Department of Clinical Sciences and Translational Medicine, Dental School, University of Rome "Tor Vergata", Rome, Italy

${ }^{3}$ Department of Surgical Sciences, Dental School, Catholic University of Our Lady of Good Counsel of Tirana, Tirana, Albania

Corresponding Author: Leonardo Gianni, Department of Clinical Sciences and Translational Medicine, Dental School, University of Rome "Tor Vergata", Rome, Italy, Phone: +39 0620900396, e-mail: leonardogianni1992@gmail.com

How to cite this article: Campanella V, Gianni L, Libonati A, et al. Shaping Ability of Reciproc R25 File and Mtwo System Used in Continuous and Reciprocating Motion. J Contemp Dent Pract 2020;21(2):171-177.

Source of support: Nil

Conflict of interest: None

using one single-use reciprocating NiTi file eliminating the need for multiple sizes, thus reducing working time. ${ }^{14}$

Dentsply Reciproc (VDW, Munich, Germany) is one of the RSF systems available on the market and is manufactured with a new NiTi alloy called M-wire (Dentsply Tulsa Dental Specialties, Tulsa, OK). The M-wire alloy has improved mechanical and physical properties, and in conjunction with the design and the reciprocating motion of the instrument is meant to enhance resistance to torsional stresses and cyclic fatigue. ${ }^{15-17}$ Reciproc files are designed to cut in counterclockwise rotation and disengage on clockwise rotation. 
In the reciprocating movement, this kind of instrument proceeds toward the apex since the counterclockwise (CCW, cutting direction) rotation angle is larger than the clockwise (CW, release direction).

In this study, Reciproc was compared to the well-known Mtwo (Sweden and Martina, Padova, Italy) instruments. Reciproc and Mtwo do have the same section design but with a mirrored image; both instruments are made of a double blade in a helical spiral. The Mtwo NiTi file has a right rotating double spiral blade cutting in a clockwise rotating motion while Reciproc has the same double blade design but with a left rotating spiral. Reciproc R25 file and the Mtwo \#25/0.06 file both have a $0.25 \mathrm{~mm}$ nonworking tip but differ in taper, blade pitch, and obviously for the different cutting motion (reciprocating or continuous rotation). R25 has a constant blade pitch from the tip to the shaft of the instrument but has variable tapers going from 0.08 in the first $3 \mathrm{~mm}$ down to 0.04 at the end of the working part. Mtwo has a constant taper of 0.06 along the entire working part but has a gradually increasing blade pitch from the tip to the shaft of the instrument.

Both systems, Reciproc R25 and full-sequence Mtwo instruments can maintain, the original canal curvature. ${ }^{18-20}$ Since these two instruments are so similar, some researchers started to investigate if the reciprocating motion applies even to instruments designed to be used in conventional continuous rotation. Some researchers compared Reciproc R25 and Mtwo \#25/0.07 used as a single file in reciprocating motion reporting similar results in terms of shaping ability. ${ }^{21}$ However, no studies are currently available on the shaping ability of a full sequence of Mtwo files used with reciprocating motion.

The purpose of this work is to compare the shaping ability of Reciproc R25 and Mtwo \#25/0.06 used as a single file, and Mtwo full sequence in a reciprocating motion. The hypothesis is that all instruments have the same shaping abilities due to cutting blade design despite the difference in NiTi alloy when used with the same motion. For comparison, we also tested in the same testing conditions the Mtwo full sequence used with conventional continuous rotation with the same sequence of files used in reciprocating motion in order to investigate if reciprocating motion produces different results in terms of canal shaping.

\section{Materials and Methods}

\section{Simulated Canals}

Forty-eight endodontic training resin blocks (Sweden and Martina) were used to test the shaping ability of NiTi files (Fig. 1). The diameter and the taper of all simulated canals were equivalent to an ISO standard size 15 root canal instrument. The radius and angle of curvature were $7 \mathrm{~mm}$ and $60^{\circ}$ according to the Pruett et al. method. ${ }^{6}$

\section{Preparation of Simulated Canals}

According to Lim et al., ${ }^{22}$ each canal sample was numbered and colored with red ink and photographed on a stand for repeatable positioning prior to any instrumentation (Fig. 2A). Specimens were randomly assigned to four different groups $(n=12)$. All experimental canals were shaped using the same torque-controlled endodontic motor (EndoPilot, Schlumbohm GmbH \& Co. KG, Brokstedt, Germany) with the 1:1 EndoPilot handpiece by one experienced clinician. This endodontic motor has continuous rotation and reciprocating motion and allows the operator to modify and set the desired reciprocating angles in both $\mathrm{CW}$ and CCW directions. Torque was set to maximum $(5 \mathrm{~N} \mathrm{~cm})$ for all test groups. Patency was confirmed for each specimen using a \#10 K-file just beyond the

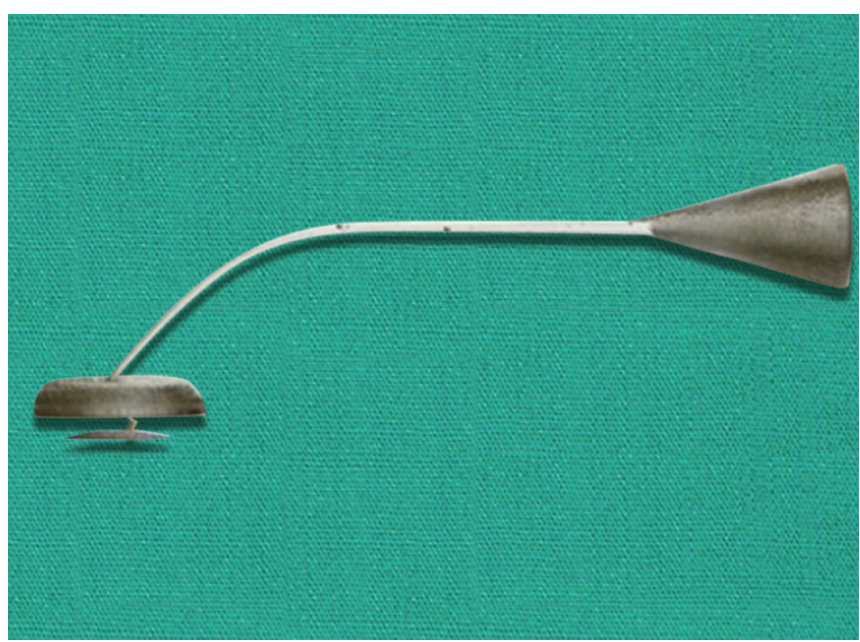

Fig. 1: An image of one of the forty-eight endodontic training resin blocks used for the study

working length. All instruments were used to enlarge four canals only. Prior to use, each instrument was coated with glycerin to act as a lubricant.

\section{Group I (Rrsf)}

The simulated canals were shaped with Reciproc R25 (VDW) used as single files in a reciprocating (at $300 \mathrm{rpm}$ ) and pecking motion until the full working length (FWL) was reached. For the progression, instruments were withdrawn from the canal after three pecking motions, or when resistance was perceived, the instrument's blades were cleaned, and the canal was irrigated with distilled water. The rotation angle was set at $150^{\circ} / 50^{\circ} \mathrm{CCW} / \mathrm{CW}$.

\section{Group II (Mrsf)}

The simulated canals were shaped with Mtwo \#25/0.06 (Sweden and Martina) used as single files in a reciprocating (at $300 \mathrm{rpm}$ ) and pecking motion until the FWL was reached. For the progression, instruments were withdrawn from the canal after three pecking motions, or when resistance was perceived, the instrument's blades were cleaned, and the canal was irrigated with distilled water. The rotation angle was set at $150^{\circ} / 50^{\circ} \mathrm{CW} / \mathrm{CCW}$.

\section{Group III (MSrec)}

The simulated canals were shaped with the Mtwo full sequence used in the same reciprocating motion of group Mrsf (300 rpm, $\left.150^{\circ} / 50^{\circ} \mathrm{CW} / \mathrm{CCW}\right)$. All Mtwo instruments were used to the full length of the canal and canal irrigation was performed after each file. The instrumentation sequence was:

- 0.04 taper size 10 instrument was used to the full length of the canal.

- 0.05 taper size 15 instrument was used to the full length of the canal.

- 0.06 taper size 20 instrument was used to the full length of the canal.

- 0.06 taper size 25 instrument was used to the full length of the canal.

\section{Group IV (MSrot)}

The simulated canals were shaped with the same Mtwo sequence used for the group III (MSrec) used in continuous rotating motion 

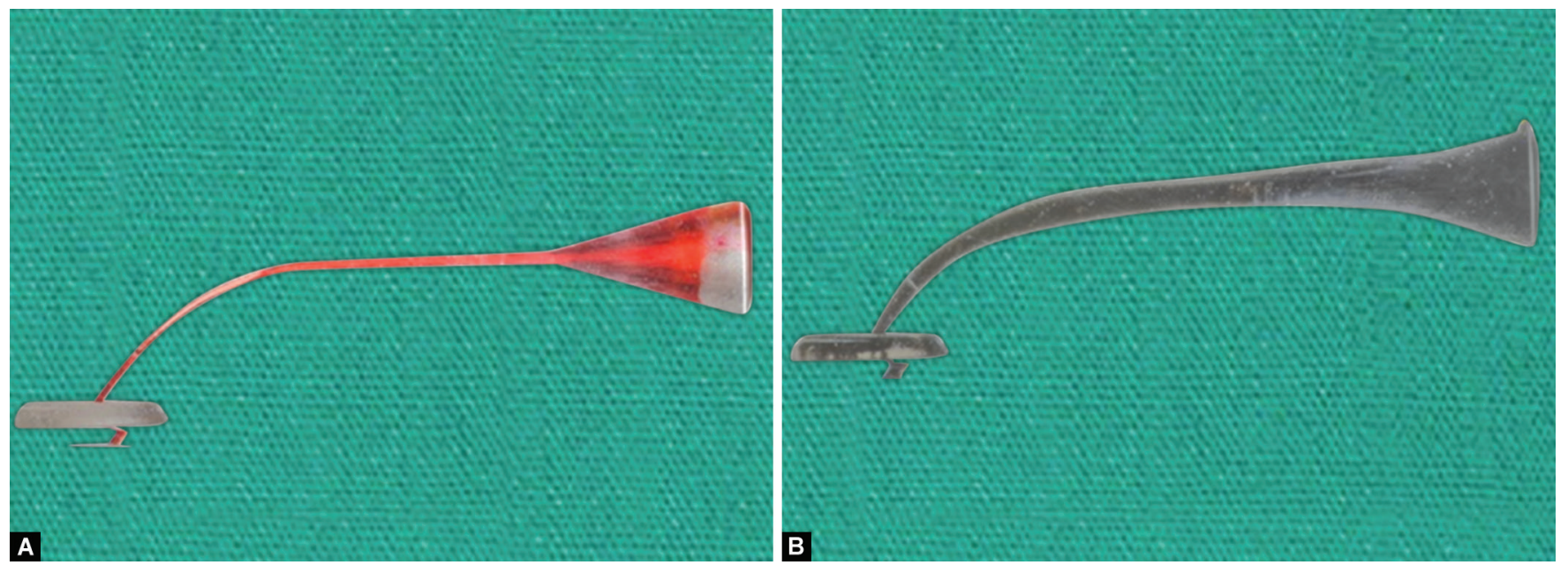

Figs 2A and B: (A) An image of canal sample numbered and colored with red ink prior to any instrumentation from group I (Rrsf); (B) An image of canal sample numbered and colored with black ink after shaping from group I (Rrsf)

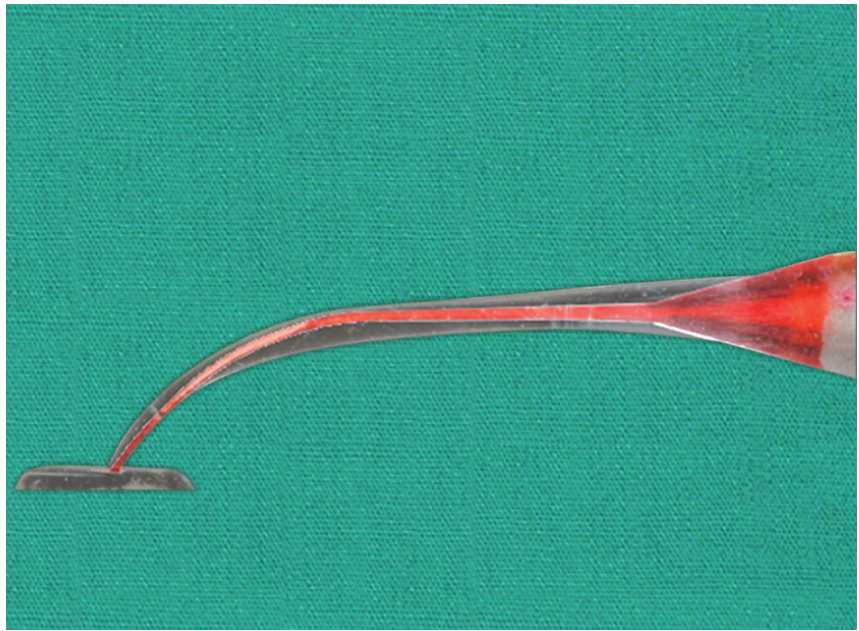

Fig. 3: Superimposing of images taken before and after the instrumentation from group I (Rrsf)

(at $250 \mathrm{rpm}$ ) and with brushing movements as advised for the technique. All Mtwo instruments were used to the full length of the canal and canal irrigation was performed after each file. All experimental tests and procedures were conducted in the lab facility of the University of Rome "Tor Vergata" by an experienced operator.

\section{Instrument Failure}

Instrument was examined under $4.5 \times$ magnification (Zeiss, Oberkochen, Germany) after every use. In case of deformation or fracture of an instrument, the endodontic training resin block was substituted, and the shaping repeated by using a new instrument.

\section{Assessment of Canal Preparation and Analysis of Data}

After shaping, each canal was colored with black ink to take a contrasting postoperative photographic image. Preoperative and postoperative images of the canals were performed in standardized conditions with a Nikon d7000 digital reflex (Nikon, Tokio, Japan) with a $105 \mathrm{~mm}$ macro lens (Fig. 2B). Each sample was positioned on a stand to ensure repeatable positioning with a fixed distance from the camera and constant lighting conditions. The images taken before and after the instrumentation, saved as high quality.jpg files (3264 × 4928), were superimposed using Adobe Photoshop (Adobe System, San Jose, CA) imaging software (Fig. 3).

Image calibration and measuring were performed by a digital image processing system (AutoCAD 2013; Autodesk Inc., San Rafael, CA, USA). The amount of resin removed, or the difference between the canal configuration before and after instrumentation was determined at both inner (convex) and outer (concave) sides of the canal curvature. Measurements were performed on 10 consecutive points of the outer and inner side of the canal. A grid composed of 10 consecutive concentric circles was superimposed to each image using the method used by Schäfer et al. to facilitate the measurement procedure. ${ }^{23}$

The ability of the instruments to remain centered in the canal was determined by calculating a centering ratio using perpendicular lines made by the canal axes at the 10 measuring points. The centering ratio was calculated using the formula $(X 1-X 2) / Y$, where $X 1$ represents the maximum extent of canal movement in one direction, $X 2$ is the movement in the opposite direction, and $Y$ is the diameter of the final canal preparation. ${ }^{22}$

All data were recorded into an EXCEL sheet (Microsoft, Redmond, Washington, United States), and the analysis was performed using the SPSS program (version 15.0, SPSS, Chicago, Ilinois, USA). Descriptive statistics consisted of the mean \pm standard deviation for the parameter with Gaussian distributions (after confirmation with histograms and the Kolgomorov-Smirnov test).

Comparison of continuous variables was performed with analysis of variance (ANOVA) to 2 factors with Bonferroni correction (Bonferroni post hoc test). A $p$ value of $<0.05$ was considered statistically significant.

\section{Results}

The result of the assessment of canal enlargement, or the total resin removed, are summarized in Table 1. From measuring points 1-7, group Rrsf produced a greater enlargement of the canal, compared to groups Mrsf, MSrec, and MSrot $(p<0.05)$. The group MSrot produced a lower enlargement compared to groups Rrsf, Mrsf and MSrec at points 3, 5, 6, 7, and 8, and compared to groups Rrsf and Mrsf at point $4(p<0.05)$. Group MSrec produced a greater 
Reciproc R25 vs Mtwo System

Table 1: Mean values $(\mathrm{mm})$ and standard deviation $(\mathrm{mm})$ of canal enlargement produced by the four groups

\begin{tabular}{ccccc}
\hline \multirow{2}{*}{$\begin{array}{c}\text { mm from the } \\
\text { apex }\end{array}$} & \multicolumn{4}{c}{ Groups } \\
\cline { 2 - 5 } & $I$ (Rrsf) & $I I$ (Mrsf) & $I I I($ MSrec) & $I V($ MSrot) \\
\hline 1 & $0.25 \pm 0.05^{\mathrm{a}}$ & $0.16 \pm 0.03$ & $0.16 \pm 0.03$ & $0.14 \pm 0.01$ \\
2 & $0.33 \pm 0.03^{\mathrm{a}}$ & $0.24 \pm 0.04$ & $0.24 \pm 0.03$ & $0.21 \pm 0.03$ \\
3 & $0.41 \pm 0.04^{\mathrm{a}}$ & $0.34 \pm 0.04$ & $0.33 \pm 0.04$ & $0.28 \pm 0.04^{\mathrm{b}}$ \\
4 & $0.57 \pm 0.05^{\mathrm{a}}$ & $0.44 \pm 0.06$ & $0.43 \pm 0.04$ & $0.39 \pm 0.04^{\mathrm{c}}$ \\
5 & $0.70 \pm 0.05^{\mathrm{a}}$ & $0.56 \pm 0.04$ & $0.53 \pm 0.04$ & $0.48 \pm 0.04^{\mathrm{b}}$ \\
6 & $0.71 \pm 0.05^{\mathrm{a}}$ & $0.58 \pm 0.03$ & $0.56 \pm 0.04$ & $0.51 \pm 0.06^{\mathrm{b}}$ \\
7 & $0.68 \pm 0.05^{\mathrm{a}}$ & $0.62 \pm 0.04$ & $0.62 \pm 0.03$ & $0.55 \pm 0.02^{\mathrm{b}}$ \\
8 & $0.68 \pm 0.03$ & $0.67 \pm 0.03$ & $0.68 \pm 0.02$ & $0.63 \pm 0.04^{\mathrm{b}}$ \\
9 & $0.70 \pm 0.04$ & $0.73 \pm 0.03$ & $0.75 \pm 0.03^{\mathrm{d}}$ & $0.71 \pm 0.03$ \\
10 & $0.75 \pm 0.04$ & $0.79 \pm 0.03$ & $0.82 \pm 0.05^{\mathrm{e}}$ & $0.79 \pm 0.05$ \\
\hline
\end{tabular}

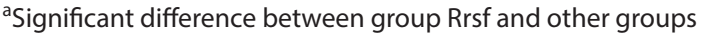

${ }^{b}$ Significant difference between group MSrot and other groups

'Significant difference between group MSrot and groups Rrsf and Mrsf

${ }^{\mathrm{d}}$ Significant difference between group MSrec and groups Rrsf and MSrot

eSignificant difference between group MSrec and group Rrsf

Table 2: Mean values $(\mathrm{mm})$ and standard deviations $(\mathrm{mm})$ of canal enlargement on both inner and outer sides produced by the four groups. Int. stands for "Inner side"; Est. stands for "Outer side"

\begin{tabular}{|c|c|c|c|c|c|c|c|c|}
\hline \multirow{3}{*}{$\begin{array}{l}\text { mm from the } \\
\text { apex }\end{array}$} & \multicolumn{8}{|c|}{ Group } \\
\hline & \multicolumn{2}{|c|}{ I (Rrsf) } & \multicolumn{2}{|c|}{ II (Mrsf) } & \multicolumn{2}{|c|}{ III (MSrec) } & \multicolumn{2}{|c|}{ IV (MSrot) } \\
\hline & Int. & Est. & Int. & Est. & Int. & Est. & Int. & Est. \\
\hline 1 & $0.05 \pm 0.03$ & $0.20 \pm 0.07^{a}$ & $0.05 \pm 0.03$ & $0.12 \pm 0.05$ & $0.05 \pm 0.03$ & $0.11 \pm 0.04$ & $0.07 \pm 0.02$ & $0.08 \pm 0.03$ \\
\hline 2 & $0.06 \pm 0.04$ & $0.27 \pm 0.06^{\mathrm{a}}$ & $0.10 \pm 0.05$ & $0.14 \pm 0.05$ & $0.09 \pm 0.03$ & $0.15 \pm 0.04$ & $0.09 \pm 0.02$ & $0.12 \pm 0.02$ \\
\hline 3 & $0.18 \pm 0.04$ & $0.23 \pm 0.05^{\mathrm{a}}$ & $0.22 \pm 0.04^{\mathrm{e}}$ & $0.12 \pm 0.05$ & $0.17 \pm 0.04$ & $0.15 \pm 0.03$ & $0.16 \pm 0.04$ & $0.12 \pm 0.03$ \\
\hline 4 & $0.38 \pm 0.04^{c}$ & $0.19 \pm 0.03^{a}$ & $0.35 \pm 0.04^{f}$ & $0.10 \pm 0.04$ & $0.31 \pm 0.04$ & $0.12 \pm 0.04$ & $0.29 \pm 0.05$ & $0.10 \pm 0.02$ \\
\hline 5 & $0.52 \pm 0.03^{\mathrm{a}}$ & $0.18 \pm 0.04^{\mathrm{a}}$ & $0.48 \pm 0.03^{f}$ & $0.08 \pm 0.03$ & $0.44 \pm 0.04$ & $0.08 \pm 0.04$ & $0.42 \pm 0.04$ & $0.06 \pm 0.02$ \\
\hline 6 & $0.54 \pm 0.06^{d}$ & $0.17 \pm 0.06^{a}$ & $0.52 \pm 0.04$ & $0.06 \pm 0.04$ & $0.49 \pm 0.06$ & $0.07 \pm 0.04$ & $0.47 \pm 0.06$ & $0.04 \pm 0.04$ \\
\hline 7 & $0.42 \pm 0.06$ & $0.26 \pm 0.06^{b}$ & $0.43 \pm 0.05$ & $0.19 \pm 0.06$ & $0.40 \pm 0.05$ & $0.22 \pm 0.05$ & $0.36 \pm 0.04^{g}$ & $0.19 \pm 0.05$ \\
\hline 8 & $0.35 \pm 0.05$ & $0.33 \pm 0.05$ & $0.37 \pm 0.05$ & $0.31 \pm 0.05$ & $0.34 \pm 0.06$ & $0.35 \pm 0.06$ & $0.28 \pm 0.05^{g}$ & $0.35 \pm 0.05$ \\
\hline 9 & $0.33 \pm 0.05$ & $0.37 \pm 0.06$ & $0.34 \pm 0.05^{f}$ & $0.39 \pm 0.06$ & $0.31 \pm 0.07$ & $0.43 \pm 0.07$ & $0.27 \pm 0.06$ & $0.44 \pm 0.06$ \\
\hline 10 & $0.32 \pm 0.05$ & $0.43 \pm 0.07^{d}$ & $0.34 \pm 0.05$ & $0.45 \pm 0.06$ & $0.32 \pm 0.07$ & $0.49 \pm 0.09$ & $0.27 \pm 0.07$ & $0.52 \pm 0.07$ \\
\hline
\end{tabular}

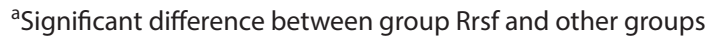

${ }^{b}$ Significant difference between group Rrsf and groups Mrsf and MSrot

'Significant difference between group Rrsf and groups MSrec and MSrot

dSignificant difference between group Rrsf and group MSrot

eSignificant difference between group Mrsf and groups MSrec and MSrot

fSignificant difference between group Mrsf and group MSrot

${ }^{9}$ Significant difference between group MSrot and groups Rrsf and Mrsf

enlargement, compared to groups Rrsf and MSrot at point 9, and compared to group Rrsf at point $10(p<0.05)$ (Table 1$)$.

Considering the results obtained at the inner and outer sides of the curved canal separately (Table 2), group Rrsf displayed a significantly greater enlargement of the canal on the outer side, compared to groups Mrsf, MSrec, and MSrot in the first 6 points, and compared to groups Mrsf and MSrot at point 7 ( $p<0.05$ ). On the inner side, group Rrsf displayed a significantly greater enlargement at point 4, compared to groups MSrec and MSrot, at point 5, compared to groups Mrsf, MSrec, and MSrot, and at point 6, compared to group MSrot $(p<0.05)$. Group Rrsf displayed a significantly lower enlargement of the canal on the outer side at point 10, compared to group MSrot $(p<0.05)$. Group Mrsf displayed a significantly greater enlargement of the canal at the inner side at point 3, compared to groups MSrec and
MSrot, at points 4, 5, and 9, compared to group MSrot $(p<0.05)$. At the inner side, group MSrot displayed a significantly lower enlargement at points 7 and 8 compared to groups Rrsf and Mrsf $(p<0.05)$.

The mean centering ratio was significantly lower in group Rrsf compared to groups MSrec and MSrot at point 1 and compared to groups Mrsf, MSrec, and MSrot at point 2 ( $p<0.05$ ). Group Mrsf displayed a significantly higher centering ratio compared to groups Rrsf and MSrec at point $3(p<0.05)$. The mean centering ratio was significantly lower in group MSrot compared to groups Rrsf and Mrsf at point 8 and compared to group Mrsf at point 9 $(p<0.05)$ (Table 3).

Two simulated canals of group Mrsf were discarded because of a visible deformation of the blades, but no instrument showed fractures or separations. 
Reciproc R25 vs Mtwo System

Table 3: Mean values and standard deviation of centering ratio produced by the four groups

\begin{tabular}{ccccc}
\hline \multirow{2}{*}{$\begin{array}{c}\text { mm from the } \\
\text { apex }\end{array}$} & \multicolumn{4}{c}{ Groups } \\
\cline { 2 - 5 } & $I$ (Rrsf) & \multicolumn{1}{c}{ II (Mrsf) } & \multicolumn{1}{c}{ (MSrec) } & \multicolumn{1}{c}{ IV (MSrot) } \\
\hline 1 & $-0.42 \pm 0.14^{\mathrm{a}}$ & $-0.30 \pm 0.15$ & $-0.27 \pm 0.12$ & $-0.17 \pm 0.10$ \\
2 & $-0.45 \pm 0.13^{\mathrm{b}}$ & $-0.23 \pm 0.16$ & $-0.27 \pm 0.11$ & $-0.21 \pm 0.05$ \\
3 & $-0.19 \pm 0.10$ & $0.01 \pm 0.12^{\mathrm{c}}$ & $-0.11 \pm 0.09$ & $-0.10 \pm 0.09$ \\
4 & $0.15 \pm 0.07$ & $0.20 \pm 0.06$ & $0.14 \pm 0.09$ & $0.13 \pm 0.07$ \\
5 & $0.34 \pm 0.06$ & $0.38 \pm 0.05$ & $0.34 \pm 0.08$ & $0.34 \pm 0.06$ \\
6 & $0.37 \pm 0.12$ & $0.45 \pm 0.08$ & $0.40 \pm 0.10$ & $0.42 \pm 0.09$ \\
7 & $0.16 \pm 0.11$ & $0.22 \pm 0.10$ & $0.16 \pm 0.11$ & $0.13 \pm 0.09$ \\
8 & $0.03 \pm 0.10$ & $0.05 \pm 0.09$ & $-0.01 \pm 0.12$ & $-0.09 \pm 0.09^{\mathrm{d}}$ \\
9 & $-0.04 \pm 0.10$ & $-0.03 \pm 0.09$ & $-0.09 \pm 0.13$ & $-0.16 \pm 0.11^{\mathrm{e}}$ \\
10 & $-0.07 \pm 0.10$ & $-0.06 \pm 0.10$ & $-0.10 \pm 0.13$ & $-0.19 \pm 0.13$ \\
\hline
\end{tabular}

${ }^{a}$ Significant difference between group Rrsf and groups MSrec and MSrot

${ }^{b}$ Significant difference between group Rrsf and other groups

'Significant difference between group Mrsf and groups Rrsf and MSrec

${ }^{\mathrm{d}}$ Significant difference between group MSrot and groups Rrsf and Mrsf

eSignificant difference between group MSrot and group Mrsf

\section{Discussion}

In this study, we used the EndoPilot motor. Due to patent protection, it was not possible to set the $150^{\circ}$ set up for the cutting direction and $30^{\circ}$ set up for the release direction, as recommended by the Reciproc manufacturer. Thus, the chosen closest values for the reciprocating motion cutting $150^{\circ} /$ release $50^{\circ}$ and speed $300 \mathrm{rpm}$. The endodontic motor settings for continuous rotation were 250 rpm, as indicated by the manufacturer of Mtwo. It is not possible to compare directly the different speeds between reciprocating and rotation motion, as reported by Gambarini et al. ${ }^{24}$ Use of simulated canals did not reflect the action of the instruments in root canals of real teeth because of differences in texture, hardness and cross-section of the surface. ${ }^{25}$ However, resin blocks allow a direct comparison of shaping ability among different instruments. Studies by Peters and Schäfer et al. on extracted teeth fully confirmed observation made on resin blocks. ${ }^{25,26}$ Measuring points were defined through the method of Schäfer et al. ${ }^{23}$ This method defines a constant distance increment from the apical foramen $(1 \mathrm{~mm}$ each step), thus removing any subjective factor that might influence the selection of an arbitrary measuring point.

The samples of group Rrsf showed a significant difference compared with other groups. This instrument produced a greater enlargement of the canal in comparison with the other groups in the apical and middle third (point 1-7). This greater enlargement in group Rrsf can be explained by analyzing the file diameter. In fact, R25 has a bigger diameter than Mtwo \#25/0.06 until D6. No significant difference was found between groups Mrsf and MSrec. This result suggests that the shaping ability of Mtwo \#25/0.06 used as a RSF is similar to the full sequence in a reciprocating motion. However, further studies should investigate the cleaning effectiveness of the Mtwo \#25/0.06 RSF and compare it with the full sequence Mtwo, both in a reciprocating and rotating motion.

The instrumentation of group MSrot showed a significantly lower enlargement of the canal at points 3 and $5-8$. These results are in contrast with Giuliani et al. ${ }^{27}$ These authors found that the full sequence of the ProTaper universal in continuous rotation removed a significantly greater amount of resin compared to WaveOne used as an RSF and the full sequence of ProTaper in a reciprocating motion. This opposite result may be explained by different instrument designs. Probably, Mtwo files work better in continuous rotation and brushing motion, because of its higher radial-cutting ability.

The centering ratio defines the ability of instruments to remain centered in shaped canals. According to the formula, the centering ratio approaches zero as $X 1$ and $X 2$ become closer to the center. The closer to zero are the scores, the more centered the instruments worked in the canal. A negative score indicates transportation on the outer side, while a positive score on the inner side. In the apical first three millimeters, group MSrot produced a uniform enlargement while group Rrsf produced significant transportation on the outer side of the curvature. This result suggests that file sequences with increasing diameter and taper can shape the canal up to the apex, better preserving the initial curvature. This assumption is in agreement with Berutti et al., ${ }^{28}$ the preliminary creation of a repeatable and safe glide path seems always necessary for a correct canal shaping with rotary and reciprocating NiTi files. Also, de Carvalho et al. ${ }^{29}$ demonstrated a better centering ability of the R25 Reciproc associated with a preliminary enlargement of the canal. Our results are instead in contrast with the work of Bartols et al. ${ }^{30}$ that found a more centered preparation with Reciproc R25 compared to Mtwo full sequences. The different result is probably due to the experience of the operator. In Bartols study, all simulated canals were shaped by inexperienced dental students, while in our study, the operator was a very well experienced endodontist. Even with no experience and despite the results they obtained, it is interesting that the students that worked for Bartols study found the Mtwo system the more easy to handle over Reciproc and FlexMaster. ${ }^{30}$

In the coronal third, group MSrot produced more negative centering ratios. This result is probably due to the lateral brushing movement, used only in this group (MSrot), instead of the pecking motion instrumenting technique used in all the other groups. Goldberg et al. ${ }^{31}$ reported a similar behavior of the WaveOne single-file instrumentation technique, which showed external canal transportation before curve initiation and internal at curve initiation.

During the shaping procedures of all samples, the operator experienced only two instrument failures. In two cases, in group Mrsf a Mtwo \#25/0.06 used as a RSF showed a visible deformation of 
the blades, but no fractures or separations. No instruments of group Rrsf showed deformation. The M-wire alloy and the cross-section area of these instruments, bigger for R25 than for Mtwo \#25/0.06, seems to give greater resistance to torsional stresses. All files of groups MSrec and MSrot did not show any deformation or failures. The use of these instruments in a sequence of increasing diameters appears to be the key to reduce the stresses they experience. ${ }^{32}$ De-Deus et al. ${ }^{33}$ assessed that the R25 Reciproc instrument is able to reach the FWL of straight- and moderate-curved mandibular molar canals without a glide path in a large proportion of cases but not in all cases. Further studies should evaluate the ability of different instrumentation systems and techniques to reach the FWL in severely curved canals.

\section{Conclusion}

Within the limitations of this study, the shaping of simulated canals using a sequence of instruments used in continuous rotation resulted in a more centered preparation of the apical third. The reciprocating motion for all tested instruments produced always a bigger enlargement of the canals in the apical third with the Reciproc R25 giving the highest values. In our study, the Mtwo used in sequence and in continuous rotation gave the best results in shaping the canals respecting the initial anatomy and curvature. Not all instruments have the same shaping abilities in spite of the same cutting blade design. The hypothesis that the NiTi alloy is secondary to the design of the blades when comparing the shaping ability of different instruments in the same reciprocating motion was confirmed, even if in two cases Mtwo showed deformations when used as a single file.

\section{Clinical Significance}

Reciprocating movement results in a more pronounced canal enlargement but appears to be less respectful of the original canal curvature and produces more apical transportation than a sequence of rotary NiTi files with the same ending apical size.

\section{Limitation of the Study}

The present study has some limitations to be considered. This study was conducted on training resin blocks with simulated canals. This is a good way to standardize samples previously used in many other research studies, but there are obviously differences in the cutting ability of $\mathrm{NiTi}$ instruments in a plastic matter rather than in human root canals.

\section{References}

1. Schilder $\mathrm{H}$. Cleaning and shaping the root canal. Dent Clin North Am 1974;18(2):269-396.

2. Waila HM, Brantley WA, Gerstein H. An initial investigation of the bending and torsional properties of nitinol root canal files. J Endod 1988;14(7):346-351. DOI: 10.1016/S0099-2399(88)80196-1.

3. Parashos $\mathrm{P}, \mathrm{Messer} \mathrm{HH}$. Rotary NiTi instrument fracture and its consequences. J Endod 2006;32(11):1031-1043. DOI: 10.1016/ j.joen.2006.06.008.

4. Thompson SA, Dummer PMH. Shaping ability of ProFile 0.04 taper series 29 rotary nickel-titanium instruments in simulated root canals. Part 2. Int Endod J 1997;30(1):8-15. DOI: 10.1111/j.1365-2591.1997. tb01092.x.

5. Schäfer E, Lohmann D. Efficiency of rotary nickel-titanium FlexMaster instruments compared with stainless steel hand K-Flexfile. Part 1. Shaping ability in simulated curved canals. Int Endod J 2002;35(6):505-513. DOI: 10.1046/j.1365-2591.2002.00513.x.
6. Pruett JP, Clement DJ, Carnes Jr DL. Cyclic fatigue testing of nickeltitanium endodontic instruments. J Endod 1997;23(2):77-85. DOI: 10.1016/S0099-2399(97)80250-6.

7. Zelada G, Varela P, Martin B, et al. The effect of rotational speed and the curvatura of root canals on the breakage of rotary endodontic instruments. J Endod 2002;28(7):540-542. DOI: 10.1097/00004770200207000-00014.

8. De-Deus G, Moreira EJ, Lopes HP, et al. Extended cyclic fatigue life of F2 ProTaper instruments used in reciprocating movement. Int Endod J 2010;43(12):1063-1068. DOI: 10.1111/j.1365-2591.2010.01756.x.

9. Gavini G, Caldeira CL, Akisue E, et al. Resistance to flexural fatigue of reciproc R25 files under continuous rotation and reciprocating movement. J Endod 2012;38(5):684-687. DOI: 10.1016/ j.joen.2011.12.033.

10. Pedullà E, Grande NM, Plotino G, et al. Influence of continuous or reciprocating motion on cyclic fatigue resistance of 4 different nickel-titanium rotary instruments. J Endod 2013;39(2):258-261. DOI: 10.1016/j.joen.2012.10.025.

11. Kiefner $\mathrm{P}$, Ban $M$, De-Deus $G$. Is the reciprocating movement per se able to improve the cyclic fatigue resistance of instruments? Int Endod J 2014;47(5):430-436. DOI: 10.1111/iej.12166.

12. Shin CS, Huang $\mathrm{YH}$, Chi CW, et al. Fatigue life enhancement of $\mathrm{NiTi}$ rotary endodontic instruments by progressive reciprocating operation. Int Endod J 2014;47(9):882-888. DOI: 10.1111/iej.12233.

13. Yared G. Canal preparation using only one Ni-Ti rotary instrument: preliminary observations. Int Endod J 2008;41(4):339-344. DOI: 10.1111/j.1365-2591.2007.01351.x.

14. Bürklein S, Schäfer E. Apically extruded debris with reciprocating single-file and full-sequence rotary instrumentation systems. J Endod 2012;38(6):850-852. DOI: 10.1016/j.joen.2012.02.017.

15. Johnson E, Lloyd A, Kuttler $\mathrm{S}$, et al. Comparison between a novel nickel-titanium alloy and 508 nitinol on the cyclic fatigue life of ProFile 25/0.04 rotary instruments. J Endod 2008;34(11):1406-1409. DOI: 10.1016/j.joen.2008.07.029.

16. Pereira ES, Gomes RO, Leroy AM, et al. Mechanical behavior of M-Wire and conventional NiTi wire used to manufacture rotary endodontic instruments. Dent Mater 2013;29(12):e318-e324. DOI: 10.1016/j. dental.2013.10.004.

17. Copes HP, Gambarra-Soares T, Elias CN. Comparison of the mechanical properties of rotary instruments made of conventional nickeltitanium wire, M-wire, or nickel-titanium alloy in R-phase. J Endod 2013;39(4):516-520. DOI: 10.1016/j.joen.2012.12.006.

18. Bürklein S, Hinschitza K, Dammaschke T, et al. Shaping ability and cleaning effectiveness of two single-file systems in severely curved root canals of extracted teeth: Reciproc and WaveOne versus Mtwo and ProTaper. Int Endod J 2012;45(5):449-461. DOI: 10.1111/j.13652591.2011.01996.x.

19. Bürklein S, Benten S, Schäfer E. Shaping ability of different single-file systems in severely curved root canals of extracted teeth. Int Endod J 2013;46(6):590-597. DOI: 10.1111/iej.12037.

20. Navós BV, Hoppe CB, Mestieri LB, et al. Centering and transportation: in vitro evaluation of continuous and reciprocating systems in curved root canals. J Conserv Dent 2016;19(5):478-481. DOI: 10.4103/09720707.190008 .

21. Hwang YH, Bae KS, Baek SH, et al. Shaping ability of the conventional nickel-titanium and reciprocating nickel-titanium file systems: a comparative study using micro-computed tomography. J Endod 2014;40(8):1186-1189. DOI: 10.1016/j.joen.2013.12.032.

22. Lim YJ, Park SJ, Kim HC, et al. Comparison of the centering ability of Wave.One and Reciproc nickel-titanium instruments in simulated curved canals. Restor Dent Endod 2013;38(1):21-25. DOI: 10.5395/ rde.2013.38.1.21.

23. Schäfer E, Tepel J, Hoppe W. Properties of endodontic hand instruments used in rotary motion. Part 2. Instrumentation of curved canals. J Endod 1995;21(10):493-497. DOI: 10.1016/S00992399(06)80519-4.

24. Gambarini G, Plotino G, Sannino G, et al. Cyclic fatigue of instruments for endodontic glide path. Odontology 2013;103(1):56-60. DOI: 10.1007/s10266-013-0138-x. 
25. Peters OA. Current challenges and concepts in the preparation of root canal systems: a review. J Endod 2004;30(8):559-565. DOI: 10.1097/01. DON.0000129039.59003.9D.

26. Schäfer E, Erler M, Dammaschke T. Comparative study on the shaping ability and cleaning efficiency of rotary Mtwo instruments. Part 1. Shaping ability in simulated curved canals. Int Endod J 2006;39(3):196-202. DOI: 10.1111/j.1365-2591.2006.01074.x.

27. Giuliani V, Di Nasco L, Pace R, et al. Shaping ability of waveone primary reciprocating files and ProTaper system used in continuous and reciprocating motion. J Endod 2014;40(9):1468-1471. DOI: 10.1016/ j.joen.2014.02.024.

28. Berutti E, Paolino DS, Chiandussi G, et al. Root canal anatomy preservation of WaveOne reciprocating files with or without glide path. J Endod 2012;38(1):101-104. DOI: 10.1016/j.joen.2011.09.030.

29. de Carvalho GM, Sponchiado Jr EC, Garrido AD, et al. Apical transportation, centering ability, and cleaning effectiveness of reciprocating single-file system associated with different glide path techniques. J Endod 2015;41(12):2045-2049. DOI: 10.1016/ j.joen.2015.09.005.

30. Bartols A, Christofzik DW, Krummel M, et al. Assessment of different root canal preparation techniques with rotary nickel-titanium instruments by novice students. Dent J 2018;6(3):46-55. DOI: 10.3390/ dj6030046.

31. Goldberg M, Dahan S, Machtou P. Centering ability and influence of experience when using WaveOne single-file technique in simulated canals. Int J Dent 2012;2012:206321. DOI: 10.1155/2012/206321.

32. Yared $G$, Ramil GA. Single file reciprocation: a literature review. ENDO 2013;7(3):171-178.

33. De-Deus G, Arruda TE, Souza EM, et al. The ability of the Reciproc R25 instrument to reach the full root canal working length without a glide path. Int Endod J 2013;46(10):993-998. DOI: 10.1111/ iej.12091. 